\title{
EVALUATION OF GIS AND BIM ROLES FOR THE INFORMATION MANAGEMENT OF HISTORICAL BUILDINGS
}

\author{
G.Saygi $^{\text {a, c }}$, G. Agugiaro ${ }^{\text {b }}$, M.Hamamcioğlu-Turan ${ }^{c}$, F. Remondino ${ }^{b}$ \\ a Dokuz Eylül University, Faculty of Architecture, 35160-Izmir, Turkey \\ gamze.saygi@deu.edu.tr \\ b 3D Optical Metrology (3DOM) unit, Bruno Kessler Foundation (FBK), 38123-Trento, Italy \\ (agugiaro, remondino)@fbk.eu \\ ${ }^{\mathrm{c}}$ Izmir Institute of Technology, Faculty of Architecture, 35430-Izmir, Turkey \\ mineturan@iyte.edu.tr
}

KEYWORDS: architectural heritage, 3D model, GIS, BIM, digital archiving, data processing, information management

\begin{abstract}
:
An architectural heritage object carries heterogeneous and multi-layered information beyond physical characteristics. It requires an integrated representation of various types of information for understanding and management prior to the decision-making process of conservation. This requirement is a twofold manner consisting of representation and management processes. There exists a variety of approaches for representation of heritage objects in digital three-dimensional (3D) environment, but the selection of the appropriate one according to the needs is crucial. On one hand, there have been recently great attempts to adopt Building Information Modeling (BIM) for historical buildings. Nevertheless, the related works in the topic focus mainly on pre-processing of data, such as the integration of born-digital material into a BIM environment and the creation of parametric objects according to historical building characteristics. As the information management of a historical building requires enhanced attribute management and integration of different datasets, further investigation on the BIM capabilities in management terms is crucial. On the other hand, Geographical Information Systems (GIS) have great potentials in exploring spatial relationships, but their potential in 3D representation is still somehow limited. The paper reviews and evaluates the roles of BIM and GIS, highlighting their advantages and disadvantages for integration, retrieval and management of heterogeneous data in the context of historical buildings.
\end{abstract}

\section{INTRODUCTION}

Drawings are indispensable documents not only in architectural conservation but also in its major field, architecture, though they may show an important limitation: they are often composed of "just" geometric features and some textual annotations, without any explicit semantic and structural characterization among the various geometric features. Indeed, relational and conceptual data might be hidden beyond pure geometric data. For deciphering and assessing data beyond them, the use of information management systems is crucial. The digital management of architectural heritage information is still a complex problem, as an architectural heritage object requires an integrated representation of various types of information in order to develop appropriate conservation strategies.

\subsection{Research Aim}

Today, three dimensional (3D) digital models of architectural heritage are found as indispensable representations for heterogeneous data management. Nevertheless, moving towards 3D models from two dimensional (2D) drawings is not only the creation of volumetric objects but it is actually a more complex process, in particular "if" conservation professionals need not only to navigate through documents but also to perform spatial and multi-criteria queries in a virtual $3 \mathrm{D}$ environment for taking conservation decisions. If this is the case, a "simple" $3 \mathrm{D}$ geometric object is in fact not enough, as it lacks for example any information about its internal structure and the mutual relations between the compounding architectonical elements. Therefore, such conceptual organization is of great importance, as a cognitive representation is needed. If the geometric 3D model is enriched by means of such mutual and hierarchical relationships, then access to the information through a digital 3D model can be more efficient. Consequently, a management process indicates three main stages, i.e. the conceptual modeling phase, data structuring phase and the data representation phase.
With the above mentioned points in mind, the motivation of this paper is to present the roles, potentials and distinctions of Building Information Modeling (BIM) and Geographical Information Systems (GIS) in systematic conceptualization, structuring and representation of the architectural heritage data for its exploration and better understanding. Both BIM and GIS approaches have been tested on a historical building, using as case study Kurşunlu Khan (Manisa, Turkey). Throughout the experimentation, Autodesk AutoCAD 2011 has been the tool for 2D drafting, while Autodesk Revit Architecture 2013 is employed for the BIM approach. Esri ArcGIS 10.1 with compatible 3D modeling software Trimble SketchUp 7.0 and Autodesk 3DS are used for testing the GIS approach. In addition, the use of born-digital data is beyond the initial goals of this study as we mainly focus on representation and structuring of the archival and historical data, both in graphical and non-graphical formats.

\subsection{Related Works}

Till today, only a few researches have focused on data management at single-building scale with Geographical Information Systems, but in these studies the subject is bounded to limited concepts (Guarnieri et al. 2010; Stefani et al., 2010), which is not leading us to understand heritage values such as the historical, social, cultural, architectural ones, etc. corresponding both to scientific and educational aspects. There are also researches investigating different information systems (De Luca et al, 2011; Pecchioli et al., 2011), and focused at urban and archeological scale (Meyer et al., 2007; Agugiaro et al., 2011). Each one of these studies is invaluable in the subject but they are not offering a general approach which architect-restorers can easily apply and widely use for managing information related to historical buildings. Finally, there are researches making use of Building Information Modeling (Fai et. al, 2011; Apollonio et al., 2012; Murphy et al. 2013), but they are focused more on integrating born-digital data into the information system and not to the management phase. In addition, data processing for 
enhanced data management tailored at decision support systems (DSS) for conservation purposes are not considered yet, so this subject of research has not come to a definite solution, yet.

\section{UNDERSTANDING ARCHITECTURAL HERITAGE}

Understanding of any component of heritage is beyond understanding the physical characteristics of existing building, because each individual heritage object is a message from the past, and it remains as living witnesses of the age's tradition (The Venice Charter, 1964). All elements of architectural heritage are irreplaceable expressions of the diversity of culture (European Charter of the Architectural Heritage, 1975). In conservation discipline, the architect-restorers' aim is to preserve the aesthetic and historic value of the monument (The Venice Charter, 1964). In this context, architectural heritage objects are not only physical artifacts but they also have intangible values. Such values are also crucial for answering the questions of "what", "why" and "how" to conserve those objects (Avrami et al., 2000). Recording and assessment are the first phases helping us to answer these questions and supporting the decision-making phase. These steps are essential in order to firstly acquire knowledge for advanced understanding of architectural heritage, secondly to involve the people in the preservation of the heritage through the dissemination of the recorded information, and thirdly to ensure the maintenance and the conservation of the heritage (Letellier, 2007). In this frame, it is crucial to manage heritage information based on correct documentation and assessments so that its holistic conservation can be achieved.

\section{REPRESENTING ARCHITECTURAL HERITAGE}

The use of drawing in architecture is not just a process of passive transcription. It is mainly an analysis, conceptualization and projection tool (Lichtenstein, 1989). Therefore the representation is a knowledge extraction problem (De Luca et al., 2006). One can easily capture the same concept not only with manual but also with semi-automated or automated methods prior to representations regarding architectural heritage. Whichever method is used, it is important to understand the shape and geometry of the building elements in depth; only then, it is possible to represent the building appropriately.

On the other hand, in recent years, architects and restorers have started to use computer-based techniques more and more frequently due to the advantages the digital technologies possess such as tools for digital data acquisition, digital reconstructions, virtual-museum applications, etc. These advances in information technologies allow researchers to represent digitally historical buildings in 3D. This becomes an important topic, as 3D models are not just visualization, but also representation of the architectural features, history, values, etc. Furthermore, access to the information through a digital 3D model as an interface is considered one of the most efficient ways for better comprehension. Regarding the geometric models, there are mainly two 3D modeling paradigms (Kolbe and Plümer, 2004), namely the Constructive Solid Geometry (CSG) and Boundary Representation (B-Rep) (Figure 1). In the B-Rep approach, one needs to define each surface of a volume as a (set of) polygon(s), whereas in CSG each geometry is defined as a volumetric object. If one thinks about modeling a simple prism, he/she needs to draw six surfaces with B-Rep, while he/she needs only three parameters (height, width and depth) for one single object with CSG. Both modeling paradigms have pros and cons; and the crucial decision is to select the right method corresponding to the project needs.

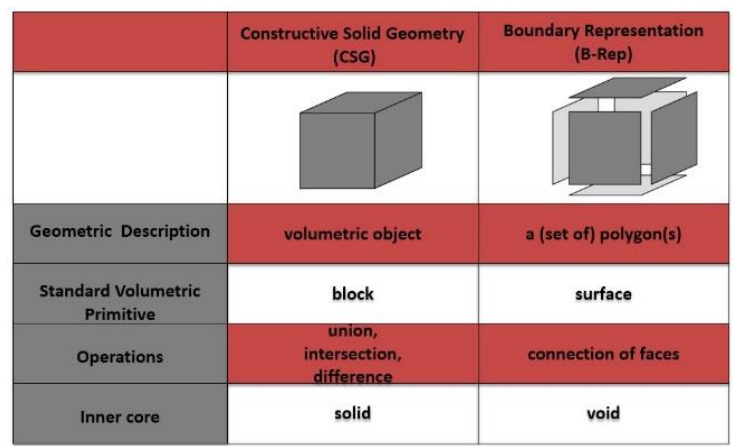

Figure 1. Comparison of CSG and B-Rep paradigms.

Besides geometry, architectural heritage objects carry a large amount of heterogeneous data because of their physical and historical complexity. Because of that, a large amount of heterogeneous information exists beyond 3D data (De Luca et al., 2011). In this frame, representations must be structured according not only to definitional but also to relational characteristics. At the same time, it is essential to integrate different kinds of data to the geometrical features for accessing and structuring information.

\section{MANAGING ARCHITECTURAL HERITAGE INFORMATION}

Management of architectural heritage information is crucial for better understanding heritage data, and for the development of appropriate conservation strategies. The management process involves generation of both $2 \mathrm{D}$ and $3 \mathrm{D}$ digital visualizations, definition of parameters and relations among the data, structuring those, and representing structured data through visualizations. Therefore, for better comprehension a crucial point in a database system is the possibility to integrate and manage heterogeneous data that will be linked to a multilayered 3D model.

\subsection{Building Information Modeling}

Building Information Modeling (BIM) offers an integrated approach for overall design, construction and post-construction process in architectural and engineering industry (Eastman et al., 2008). The system follows the Constructive Solid Geometry (CSG) modeling paradigm. Nevertheless, building components are more "intelligent" in BIM: building elements are not only graphical expressions, but they also own shape attributes. From a geometrical point of view, each element is a parametric object and we can automatically modify or update it by changing parameters and rules. Moreover, BIM provides the possibility to represent all views (3D model, plans, sections, elevations, and details) automatically. By these means, it offers improved visualization and coordination between drawings.

\subsection{Geographical Information Systems}

Information produced during the documentation and analysis phases is huge in quantity and characterized by huge heterogeneity. At this point, information technologies also help us to organize and structure the data. There are (some) prejudices regarding Geographical Information Systems (GIS) when applied to heritage buildings, as the term "geographical" is understood as if it would refer to only $\mathrm{X}, \mathrm{Y}, \mathrm{Z}$ coordinates. However, a GIS is not bounded to a local or global situation, it 
refers to spatial relationships. In this frame, GIS are computerized systems designed for the storage, retrieval and analysis of geo-spatial data. Till today, GIS proved their great potentials in exploring spatial relationships of demographic, cultural, economic and geographic areas, but their potential in management of architectural heritage information at singlebuilding scale has not come to light, yet.

\subsection{A Case Study: Kurşunlu Khan in Turkey}

As the main motivation is to make use of existing data, the best approach was to select a building typology that has been extensively studied. In this context, a $15^{\text {th }}$ century khan*, namely Kurşunlu Khan (Manisa, Turkey) is chosen. Kurşunlu Khan had a series of alterations and different interventions carried out in different time periods, mainly in the $19^{\text {th }}$ century and at the beginning of the second half of the $20^{\text {th }}$ century and today (Figure 2). This leads to a layered superstructure, which is very common in historical buildings. By this means, the chosen case study is also suitable for illustrating architectural, spatial, temporal changes and related analysis.
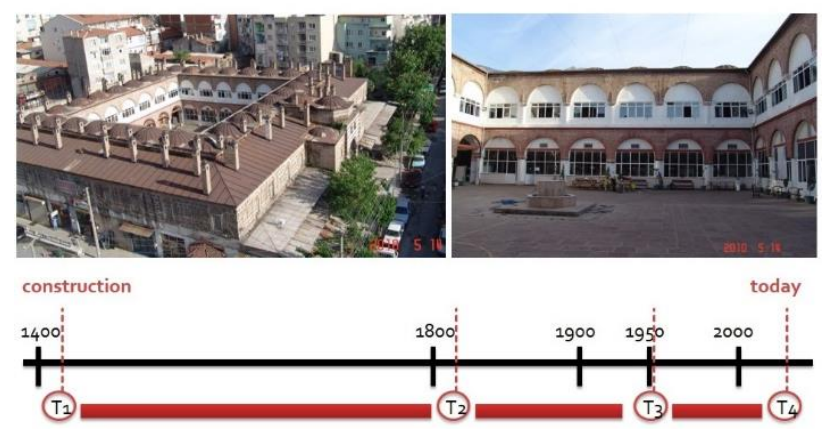

Figure 2. Kurşunlu Khan in Manisa, Turkey.

4.3.1. Available Data and Conceptual Modeling: Data gathered through archival and historical research are classified mainly into three groups:

1. Textual data (archival information, written documents);

2. Raster data (photographs, maps, scanned documents);

3. Vector data (2D measured drawings, sections, details; building's geographical location, neighborhood).

All data types share a common ground, namely the building elements, such as walls, columns, openings, flooring, ceiling, etc. Therefore, a better management of architectural heritage information necessitates structuring according to these elements. The data to be linked to the building elements are categorized into the following themes:

1. Descriptive texts;

2. Photographs;

3. Textual data on architectural and spatial characteristics;

4. 2D digital drawings;

5. Alterations;

6. Structural and material analysis;

7. Temporal phases, sources and reliability;

8. Interventions.

Regarding the 3D model to be created, it is fundamental to define in advance a list of all architectonical elements we may

\footnotetext{
* khan is a type of inn built within towns that effectively functioned as a trading center and hostel; and was intended primarily for people, providing food as well as shelter for travelers and traders (Encyclopedia
} Britannica, 2013). need for the khan, as well as the hierarchical and mutual relationships between different elements (please see Figure $\mathbf{7}$ in Appendix A for a formal representation as UML diagram). In order to achieve that, defining an ontology is indispensable for covering all attributes related to geometries, relationships and hierarchies (Kolbe and Plümer, 2004).

At the same time, it is important to identify and organize the workflow pipeline presented in Figure 3 and Figure 4, which is intentionally planned to remain technology independent, with the goal to test whether how and to which extent a BIM or a GIS environment would allow us to implement it without too many changes. Digitization and sub-categorization of the building into architectural elements phases share in fact the same conceptual approach in both BIM and GIS experimentations.

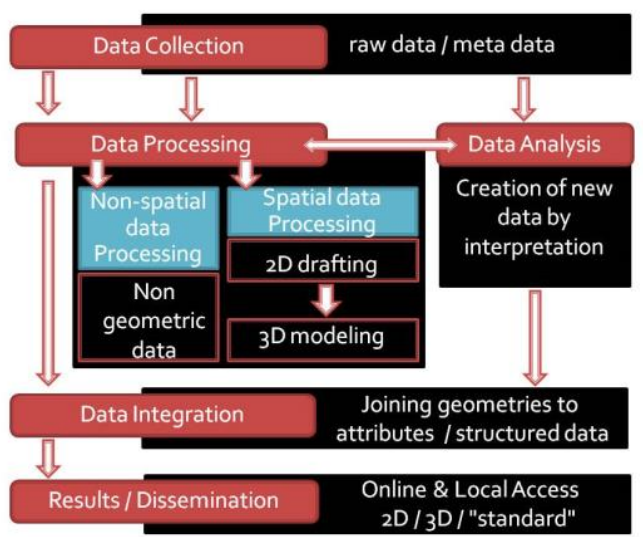

Figure 3. General workflow of the research.

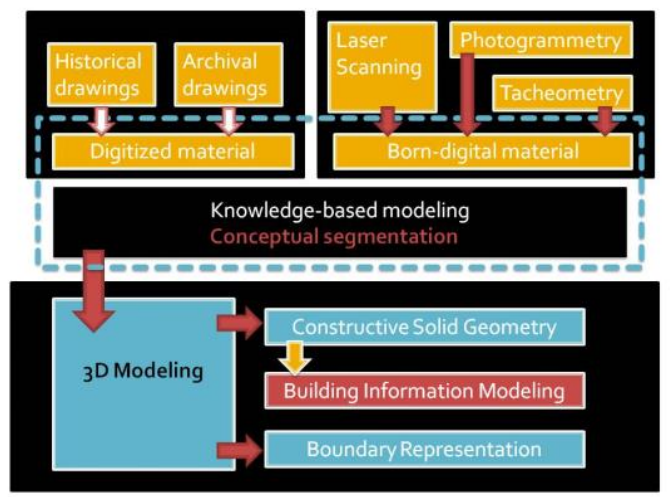

Figure 4. Extensive pipeline of spatial data processing.

Another important aspect is the conversion of archival graphical data into digital format; nevertheless, this is a quite straightforward process, as computer based techniques are developed. The critical point in this phase is however the digitizing errors because of the line weights as hand drawings lead to uncertainty, and possible site survey errors. Therefore, we work with mid-range accuracy in which there can be up to $\pm 10 \mathrm{~cm}$ inaccuracy with regards to the real world measures. This corresponds to line inaccuracies up to $\pm 1 \mathrm{~mm}$ in the 2D drawing (given for example a scale of $1: 100$ ).

4.3.2. Experimentation with BIM: With respect to the data processing in a BIM environment, some initial tests were performed within Autodesk Revit Architecture 2013. Revit is based conceptually on elements (Figure 5) such as model elements (consisting of building elements), view elements (representing different 2D and 3D viewpoints), datum elements 
(representing grids, plans, etc.), and view-specific elements represent annotations. More in details, the model elements are categorized according to typological classes, which are called families.

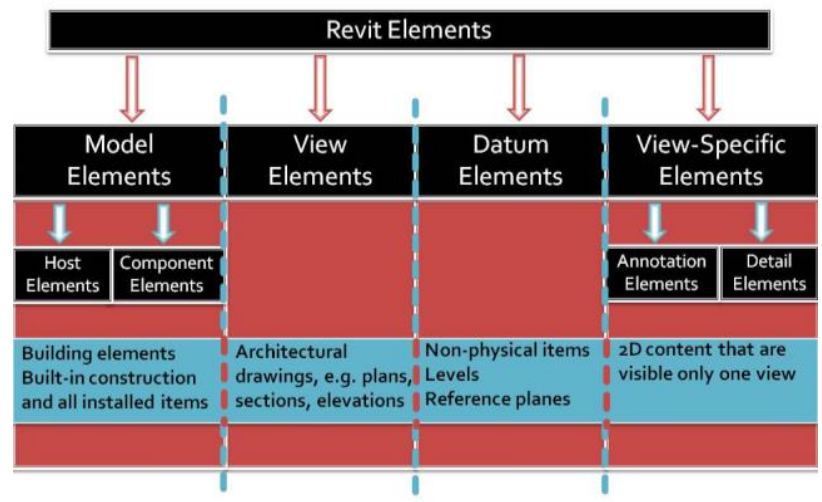

Figure 5. Elements and Families in Autodesk Revit

(Source: wikihelp.autodesk.com/Revit/enu/2014).

There exist several libraries of building elements in Revit environment. However, one of the first drawbacks is due to the fact that a historical building requires the creation of new architectural elements, namely "new component families" in Revit. Each architectural element is different from each other as at that time period there was no industrialization in construction. Each architectural element (e.g. wall, column, arch) varies in characteristics and carries different parameters. So, there is a great diversity in the characteristics of each element of a historic building; moreover, these types of specific elements are not covered in any BIM environment, representing therefore a problematic aspect tied to the BIM-based approach.

The creation of new elements and families is a process which is indeed extremely time-consuming, but if once new families are created according to construction technique and architectural style (e.g. buttress, cross vault, ionic column), an extended architectural elements library is generated. Afterwards, it is possible to modify these elements by simply changing parameters. After completing spatial data processing, it allows the integration of the generated 3D model with non-spatial data with the help of add-ins, e.g. Autodesk Revit DB Link, which provides the connection to external tables in Excel, Access or to any ODBC-compliant data-source.

Another critical aspect throughout our experimentation is the integration of new elements and the definition of families according to other criteria than those predefined in the software is inconvenient. Grouping and hierarchically relating them to each other is indeed a complicated process. This allows us to stress out that BIM is still problematic for both creating uncommon elements and hierarchically relating them.

4.3.3. Experimentation with GIS: Concerning the data processing in a GIS environment, the database was structured in order to exploit the advantages of Geographical Information Systems for the management of the architectural heritage data.

Regarding the geometric modeling, firstly, the whole building is generated in a bottom-up approach, according to the proposed hierarchy. Starting from the single architectural elements, they are modeled and grouped together recursively. In this context, Autodesk AutoCAD is used for 2D drafting, while Trimble SketchUp and Autodesk 3DS are employed for 3D modeling step as compatible software with Esri ArcGIS. A base set of 2D drawings and a 3D model is created in order to add different layers of information to create thematic maps. In addition, each building element is tagged with a specific ID in a systematic way. This allows us to organize data in different data sets, and to relate them to themes. Following this, tables consisting a variety of attributes are created for assigning different themes and organizing non-spatial data. Afterwards, in ArcGIS environment, spatial and non-spatial data is integrated i.e., attributes are joined to related building elements.

To this extent, the resulting database system gives the architectrestorer and conservation professionals the opportunity to locally access the data. It is possible to do single or multiple queries, and a simple navigation through the $3 \mathrm{D}$ model by means of ArcScene. In a GIS environment it is also possible to integrate more features, e.g. different datasets such as photographs, textual descriptions, and 2D thematic drawings. This system provides conservation professionals a better comprehension for both tangible and intangible features of the heritage object.

\subsection{Bridging the Gap}

It is possible to create and access semantically-rich objects in GIS environment (Kolbe and Plümer, 2004). In this context, attributes can be easily joined to geometries and a relational database can be built in GIS, although "standard" GIS products are still limited with regards to 3D editing functionalities. They generally only allow construction of simple 3D elements as geometric primitives. So, creating and visualize complex 3D models using a GIS software can be still problematic. In order to solve this, any compatible CSG or B-Rep software can be used for modeling, coupled with some plug-ins for importing/exporting, but this inevitably makes the process longer. As an exemplification, we can create detailed 3D models in Autodesk 3DS or Trimble Sketch Up and import them into GIS environment with the use of plug-ins. However, in the conversion process, as the geometrical schemes and related descriptions are different and (sometimes) not compatible at all, some information might be lost during the process, so that particular attention must be paid during this phase.

On the other hand, in a BIM environment "intelligent" architectural elements and 3D digital models can be created. They consist of full architectural properties (dimensions, material, texture, etc.), but there is a lack of integration of new attributes different than the architectural properties. More importantly, these elements are bounded to the specific library of BIM software. Creation of new elements and families is a long manual process, especially if we think that "historical" buildings are often composed of "non-standard" elements, or some architectonical features might be not used anymore, as BIMs are conceived for modern buildings. Today, there is a great attempt to increase BIM capabilities for more comprehensive, sophisticated and query-able characteristics, but there are no applications covering all these characteristics, yet (Garagnani \& Manferdini, 2013). There are researches on predata processing and integration of data in BIM for historical buildings, but the concern is on data exchange and integration of born-digital material into BIM environment (e.g. GreenSpider plug-in for Autodesk Revit 2012, as shown in Garagnani \& Manferdini, 2013). However, post-data processing for attribute enhancement and integration of different datasets is unresolved.

The Industry Foundation Classes (IFC), a standard data format developed by international Alliance for Interoperability, aims to 
cover both geometries and semantics (Kolbe and Plümer, 2004). Recently new attempts for post-data processing and data management have been presented, both as open and commercial software solutions. Examples are Building Information Modelserver (http://bimserver.org/) based on IFC format, the Open BIM movement initiated by Graphisoft, Tekla and buildingSMART (http://www.graphisoft.com/openbim/) for enrichment of attribute data related to building elements, zones or complete buildings. Nevertheless, enhanced attribute management is not an integral part of them, yet. Therefore the integration of external attribute data is at the moment not fully covered. In addition, an architectural heritage object necessitates an integrated representation of different thematic drawings. This requires a multi-layered modeling approach in which we can select a theme (e.g. alterations, structural system and material usage) and represent it in a multi-layered 3D environment. Although, BIM allows temporal (4D) representations, other thematic representations are beyond capabilities of today's BIM approaches.

Therefore, today there is a great need, hence significant interest in the scientific community to bridge the gap in the information management of historical buildings, but as a multidisciplinary collaboration between information technologists and conservation professionals is needed, so it might still take some time to eventually bridge the gap.

\section{CONCLUSIONS AND FUTURE PERSPECTIVE}

In this study, we have reasoned about, tested and gathered experience of some capabilities of BIM and GIS through workflows for $3 \mathrm{D}$ modeling and information management of historic buildings prior to decision-making process of conservation (Figure 6). This does not helps only management of heritage information for conservation planning purposes, but also it has digital archiving benefits.

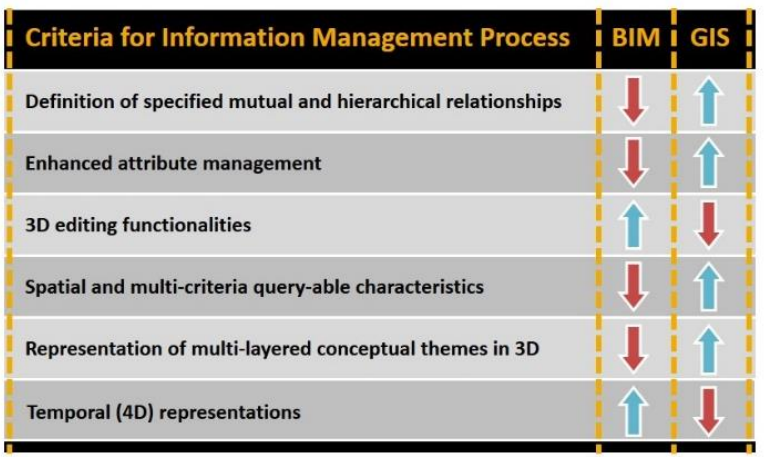

Figure 6. Pros and cons of BIM and GIS for information management of historic buildings.

The model used for the tests (Kurşunlu Khan, Turkey) provides a systematic approach. Exploiting information beyond geometry is not a simple task which goes beyond simply "applying" Information Technologies (IT) to the field of architectural conservation. It is indeed a complex cognitive process requiring the creation of an ontology, the conceptualization of relationships and the specification of hierarchies. It is, in other words, an information extraction process, which does not only provide us to build an information system but also help us to understand heritage data beyond geometric features.

There cannot be a common model in heritage conservation, as each heritage object is unique and carry individual characteristics. Nevertheless, one can adapt and calibrate pre- defined models, according to each case's specific characteristics. As ICOMOS Charter on Interpretation and Presentation of Cultural Heritage Sites (2008) underlines, the representations should also allow intellectual access to cultural heritage sites by public, an essential future work will be to create different accessibility levels for different user groups. There will be different accessibility levels considering different Level of Details (LoD) according to user needs. This will also respond to educational aspects of conservation.

Integrating semantic attributes with hierarchically and mutually segmented 3D digital geometric models is indispensable for management of heritage information and supporting decisionmaking; hence there is a great need to exchange data between different applications. However, BIM and GIS worlds still remain distinct from each other regarding the information management of historical buildings. Each of the two has advantages corresponding to diverse necessities of information management, as well as the disadvantages leading to unsatisfactory solutions. Therefore, the use of contradistinctions for establishing a sort of BIM-and-GIS integration can start up a new approach in management of historical building information management. Combination of their strong parts might give the most affective consequences as both of them concern on "information". In this context, interoperability problems must be solved and lossless data exchange must be provided. By this way, it will be possible to integrate, retrieve and manage heterogeneous data in an enhanced way.

\section{REFERENCES}

Agugiaro, G., Remondino, F., Girardi, G., Schwerin, von J., Richards-Rissetto, H., \& De Amicis R. (2011). Queryarch3D: Querying and Visualising 3D Models of a Maya Archaeological Site in a Web-based Interface. Geoinformatics FCE CTU Journal, (6), 10-17.

Apollonio, F.I., Gaiani, M., \& Zheng, S. (2012). Bim-based Modeling and Data Enrichment of Classical Architectural Buildings. SCIentific RESearch and Information Technology, 2(2), 41-62.

Autodesk Revit Architecture:

http://wikihelp.autodesk.com/Revit/enu/2014 [last access: July $\left.5^{\text {th }}, 2013\right]$

Avrami, E., Mason, R., \& De la Torre, M., (2000). Values and Heritage Conservation. S. Tidwell (Ed.) Los Angeles, USA: The Getty Conservation Institute.

De Luca, L., Véron, P., \& Florenzano, M. (2006). Reverse engineering of architectural buildings based on a hybrid modeling approach. Computers \& Graphics, (30), 160-176.

De Luca, L., Busayarat, C., Stefani, C., Véron, P., \& Florenzano, M. (2011). A semantic-based platform for the digital analysis of architectural heritage. Computers \& Graphics, 2(34), 227-241.

Eastman, C., Teicholz, P., Sacks, R., \& Liston, K. (2008). BIM Handbook: A Guide to Building Information Modeling for Owners, Managers, Designers, Engineers and Contractors. New Jersey, USA: John Wiley.

Encyclopedia Britannica:

http://www.britannica.com/EBchecked/topic/316248/khan [last access: July $\left.5^{\text {th }}, 2013\right]$ 
European Charter of the Architectural Heritage (1975). http://www.icomos.org/en/charters-and-texts/179-articles-enfrancais/ressources/charters-and-standards/170-europeancharter-of-the-architectural-heritage [last access: July $5^{\text {th }}, 2013$ ]

Fai, S., Graham, K., Duckworth, T., Wood, N., \& Attar, R. (2011). Building Information Modelling and Heritage Documentation. Paper presented at the XXIII CIPA Symposium, Prague, Czech Republic.

Garagnani, S. \& Manferdini, A.M. (2013). Parametric accuracy: Building information modeling process applied to the cultural heritage preservation. Paper presented at the 3DARCH 2013 - 3D Virtual Reconstruction and Visualization of Complex Architectures, Trento, Italy.

Guarnieri, A., Pirotti, F., \& Vettore, A. (2010). Cultural heritage interactive 3D models on the web: An approach using open source and free software. Journal of Cultural Heritage, 3(11), 350-353.

International Charter for the Conservation and Restoration of Monuments and Sites (The Venice Charter) (1964).

http://www.international.icomos.org/charters/venice_e.pdf [last access: July $5^{\text {th }}, 2013$ ]

Kolbe, T.H., \& Plümer L. (2004). Bringing GIS and CA(A)D Together - Integrating 3D city models emerging from two different disciplines. GIM International (18), 12-15.

Letellier, R. (2007). Recording, Documentation and Information Management for the Conservation of Heritage Places. Los Angeles, USA: The Getty Conservation Institute.

Lichtenstein, J. (1989). The eloquence of color: rhetoric and painting in the French Classical Age (E. McVarish, Trans.). Los Angeles, California, USA: University of California Press.

Meyer E., Grussenmeyer, P., Perrin, J.P., Durand, A., \& Drap, P. (2007). A web information system for the management and the dissemination of Cultural Heritage data. Journal of Cultural Heritage, 4(8), 396-411.
Murphy, M., McGovern, E., \& Pavia, S. (2013). Historic Building Information Modelling - Adding intelligence to laser and image based surveys of European classical architecture. ISPRS Journal of Photogrammetry and Remote Sensing, (76), 89-102.

Open Source Building Information Modelserver: http://bimserver.org/ [last access: July $5^{\text {th }}, 2013$ ]

OpenBIM: http://www.graphisoft.com/openbim/ [last access: July $5^{\text {th }}, 2013$ ]

Pecchioli, L., Carrozzino, M., Mohamed, F., Bergamasco, M., $\&$ Kolbe T.H. (2011). ISEE: Information access through the navigation of a 3D interactive environment. Journal of Cultural Heritage, 3 (12), 287-294.

Stefani, C., De Luca, L., Véron, P., \& Florenzano, M. (2010). Time indeterminacy and spatio-temporal building transformations: an approach for architectural heritage understanding. International Journal on Interactive Design and Manufacturing, (4), 61-74.

The ICOMOS Charter for the Interpretation and Presentation of Cultural Heritage Sites (2008).

http://www.international.icomos.org/charters/interpretation_e.p df [last access: July $5^{\text {th }}, 2013$ ]

\section{ACKNOWLEDGEMENTS}

Gamze Saygi has been a visiting researcher in the 3D Optical Metrology unit (3DOM) of the Bruno Kessler Foundation (FBK) in Trento (Italy) between February-August 2013 thanks to a research grant of the Turkish Council of Higher Education (YÖK), which has given her the possibility to do a part of her $\mathrm{PhD}$ research in FBK.

The work presented in this paper was also partly supported by the $3 \mathrm{M}$ project (co-founded Marie-Curie Actions FP7 PCOFOUND - GA-2008-226070, acronym "Trentino Project", Bando "Incoming Team 2009"). Moreover, the authors would like express their thanks to ARK İnsaat in Ankara, Turkey for providing drawings, pictures and reports of the selected case.

\section{APPENDIX A}

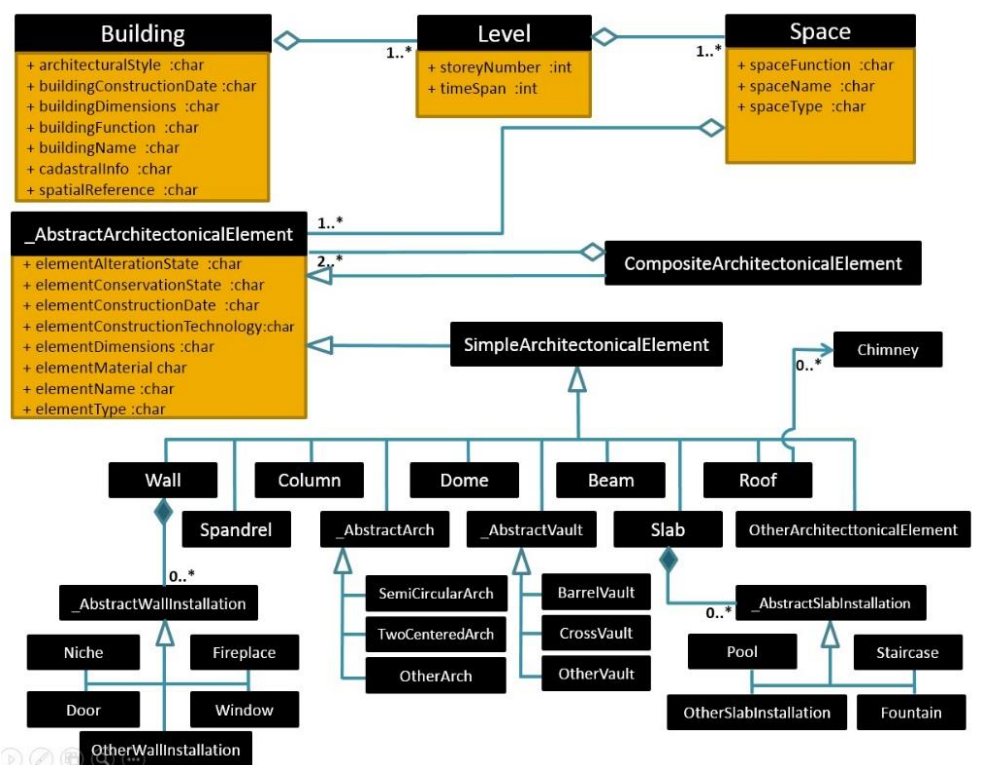

Figure 7. UML diagram representing classes and relations among the components of a historical building. 